\title{
IgA1 Protease as a Vaccine Basis for Prevention of Bacterial Meningitis
}

\author{
L. S. Zhigis ${ }^{a, 1}$, O. V. Kotelnikova ${ }^{a}$, A. A. Zinchenko ${ }^{a}$, D. M. Karlinsky ${ }^{a}$, \\ Yu. A. Prokopenko ${ }^{a}$, and L. D. Rumsh ${ }^{a}$ \\ ${ }^{a}$ Shemyakin-Ovchinnikov Institute of Bioorganic Chemistry, Moscow, 117997 Russia \\ Received August 17, 2020; revised November 15, 2020; accepted November 20, 2020
}

\begin{abstract}
The review covers the study of the protective properties of IgA1 protease and the possibility of creating a vaccine preparation for the prevention of bacterial meningitis of various origins on its basis. Bacterial meningitis belongs to the group of socially dangerous diseases and is characterized by a severe course, numerous complications and high mortality. The approaches used at present in world practice to create antimicrobial vaccines are based on a narrow targeting against a specific pathogen. The development of a monocomponent vaccine against a wide range of bacterial pathogens with a common virulence factor is still relevant. IgA1 protease, a protein that is one of the main virulence factors of a number of gram-negative and grampositive bacteria, can serve as such an antigen. Bacterial IgA1 protease is uniquely specific for immunoglobulins A1 (IgA1), cleaving peptide bonds in the hinge regions of the $\operatorname{IgA} 1$ in humans and other higher primates. Bacteria, getting on the mucous membrane, destroy IgA1, which acts as the first barrier to protect the body from infections. Neutralization of IgA1 protease at this stage can become an obstacle to the development of infection, hindering the adhesion of a number of pathogens that produce this protein. The data available in the literature on the mechanism of antibacterial protection are scattered and ambiguous. The review considers the literature data and the results of our own experiments on the protective activity of IgA 1 protease. We have shown that the recombinant meningococcal IgA1 protease and some of its fragments protect mice from infection with a live virulent culture not only of meningococci of the main epidemic serogroups (A, B, C, and W135), but also of some of the most common virulent pneumococcal serotypes. The data obtained indicate the possibility of creating a monocomponent vaccine against these and, possibly, other bacterial infections. Currently, significant progress has been made in studying the structure and functions of secreted proteins in the bacteria Neisseria meningitidis and Haemophilus influenzae. In this review we describe protein translocation systems of $N$. meningitidis, which are related to the secretion of proteins in these bacteria, and also present modern data on the functions of these proteins. Analysis of experimental data on the structure of IgA1 protease of $N$. meningitidis and the formation of immunity during vaccination is of key importance in the development of prophylactic preparations.
\end{abstract}

Keywords: IgA1 protease, Neisseria meningitidis, Haemophilus influenzae, Streptococcus pneumoniae, vaccine DOI: $10.1134 / \mathrm{S} 106816202104021 \mathrm{X}$

\section{INTRODUCTION}

Currently, the effectiveness of vaccination to protect against infectious diseases is generally recognized throughout the world. Over the past 30 years, the number of newly created vaccines has sharply increased, thanks to which more than a dozen serious infections (diphtheria, tetanus, rubella, poliomyelitis, etc.) have been eliminated or reduced to a minimum.

The approaches used in world practice to create antimicrobial vaccines are based on a narrow targeting against a specific pathogen. To protect against the

Abbreviations: IgA1, immunoglobulin A1; sIgA1, secretory immunoglobulin; OMVs, bacterial outer membrane vesicles; Hib, $H$. influenzae type b; ECM, extracellular matrix.

${ }^{1}$ Corresponding author: phone: +7 (916) 388-90-55; e-mail: zhigis@ibch.ru. whole variety of circulating and continuously mutating strains of these microbes, complex vaccination is required, including multiple administration of each component. The development, testing and production of such drugs require huge expenses, which significantly affects the cost of vaccine drugs. The high cost of the vaccines produced makes them difficult to obtain for many developing countries and complicates the process of vaccination of the general population.

The development of a monocomponent vaccine against a wide range of bacterial pathogens with a common virulence factor is still relevant, and the search for corresponding immunologically harmless protective antigens is an important research task.

One of the promising protective antigens, from the point of view creating such a vaccine, may be bacterial IgA1 protease, which is secreted by a number of gram- 
negative (Neisseria meningitidis, $N$. gonorrhoeae, Haemophilus influenzae) and gram-positive (Streptococcus pneumoniae, $S$. sanguis, $S$. oralis) bacteria [1-6]. IgA1 proteases are a family of serine (E.C. 3.4.21.72) and metal (E.C. 3.4.24.13) endopeptidases. These enzymes are characterized by unique specificity for A1 immunoglobulins, possessing the ability to cleave peptide bonds in the hinge regions of serum (IgA1) and secretory (sIgA1) A1 immunoglobulins of humans and other higher primates [4, 7]. Bacteria, colonizing the mucous membrane, destroy $\operatorname{sIgA} 1$, which is present on the mucous membrane in significant quantities and serves as the first barrier to protect the body from infections. Neutralization of IgA1 protease at this stage of invasion can hinder the development of infection, making it difficult for bacteria to adhere to the surface of the mucous membrane.

This review discusses the problems of creating a monocomponent polyvaccine for the prevention of bacterial meningitis, the causative agents of which are a wide range of gram-negative and gram-positive microorganisms, the pathogenicity of which is caused by the IgA1 protease.

\section{BACTERIAL MENINGITIS}

Bacterial meningitis is a disease with a high epidemic potential, characterized by a severe course and often fulminant in nature. Less than 24 hours can elapse between the appearance of the first symptoms, similar to those in the acute respiratory viral infections and other infectious diseases, and the development of toxic shock with a high fatal outcome, which makes it difficult to provide timely specialized care. Up to $19 \%$ of those who recover have serious long-term consequences, including neurological disorders, seizures, loss of hearing or vision, psychological disorders, loss of limbs, etc. [8-10].

The causative agents of bacterial meningitis include a wide range of pathogens of various etiologies. The main pathogens are $N$. meningitidis, $H$. influenzae and $S$. pneumoniae, which cause more than $90 \%$ of all cases of meningitis after infancy [11].

Neisseria meningitidis. Although the clinical description of meningitis as a disease appeared in the early 1880s [12], the first data on its pathogen isolated from the patient's cerebrospinal fluid were published in an article by Marchiafava et al. in 1884 [13]. Three years later, the identification and cultivation of this bacterium was described [14]. The pathogenic microorganism $N$. meningitidis, penetrating the epithelial barrier of the nasopharynx and reaching the bloodstream, causes sepsis, and overcoming the blood-brain barrier, causes toxic cerebral edema-meningitis [15, 16].

The index of morbidity caused by meningococcus can vary from $<1$ to 1000 cases per 100 thousand population, depending on the region, season, demographic data and other factors [17].
$N$. meningitidis remains one of the most common causes of meningitis in many geographic regions, including the United States, and is the only bacterium that can cause large outbreaks of the disease [18-20]. In developed countries, the mortality rate is $10-15 \%$, and in developing countries, up to $20 \%$ [12].

Based on the structure of the capsular polysaccharide, $N$. meningitidis is divided into 13 serogroups, five of which (A, B, C, W, and Y) are responsible for most meningococcal diseases.

Considering the ability of meningococcus to rapidly cause fatal and epidemic diseases around the world, understanding preventive strategies against this pathogen is a global public health priority.

The first meningococcal vaccines were based on the $N$. meningitidis capsular polysaccharides of the corresponding serogroups, however, these vaccines proved to be effective only in the adult population. Children under one year of age did not form immunity to these vaccines. In addition, polysaccharide vaccines are thymus-independent and do not affect the mechanisms of cellular immunity. Their action is based on the formation of specific antibodies only to the capsular polysaccharide of this meningococcal serogroup.

Tolerance of young children to polysaccharide vaccines has been overcome only from the end of 1990 after the creation of vaccines based on capsular polysaccharides conjugated to various protein carriers.

The advantage of conjugated vaccines is their ability, under the influence of the carrier antigen, to generate a thymus-dependent response and induce the formation of immunological memory, as well as to reduce the carrier of bacteria and, therefore, prevent the spread of infection. Of the greatest interest are 4valent vaccines against $N$. meningitidis serogroups A, $\mathrm{C}, \mathrm{W}$, and $\mathrm{Y}$ based on their capsular polysaccharides conjugated with diphtheria toxoid, intended for vaccination of people of all ages, including children from two months of age [18].

The development of an effective vaccine against the serogroup B meningococcus based on its capsular polysaccharide turned out to be problematic due to the high affinity of this antigen to gangliosides of human embryonic tissues, which is fraught with the occurrence of an autoimmune process [21]. At the same time, the morbidity of meningitis caused by the serogroup B meningococcus in some European countries reaches 64\% [22]. At the end of 2012, there was a report on clinical trials of a multicomponent vaccine 4CMenB against the serogroup B meningococcus based on proteins characteristic of a recently emerged epidemic strain, as well as three surface proteins found during sequencing of the bacterial genome [23-25].

Bacterial outer membrane vesicles (OMVs) vaccines against the serogroup $\mathrm{B}$ meningococcus have been used in many countries (Cuba, South America, Norway and New Zealand). The MeNZB vaccine used in New Zealand has been effective in reducing 
morbidity and in combating the serogroup B meningococcal epidemic [26]. The creation of a complete vaccine based on the proteins of the outer membrane of meningococcus was difficult due to the high variability of these proteins.

The vaccines MenB-4C (Bexsero; Novartis Vaccines, Italy) and MenB-FHbp (Trumenba; Wyeth Pharmaceuticals, United States) with a broader spectrum of action than OMV-based vaccines have been approved for use in the United States, with the former also being approved for use in countries of Europe, Canada and Australia [18, 23].

To date, there is a wide range of vaccines in public health practice against various serogroups of meningococcus. However, these vaccines are multicomponent and require several repeated injections, which significantly increases the antigenic load on the human body, especially young children.

Haemophilus influenzae. This pathogen is a gramnegative facultative aerobic bacillus. Based on the structure of the polysaccharide capsule, six serotypes of $H$. influenzae (a, b, c, d, e, f) are distinguished which cause invasive forms; $95 \%$ of cases are caused by serotype b.

$H$. influenzae type $\mathrm{b}(\mathrm{Hib})$, the causative agent of severe infections in children under five years of age, in different European countries in the period before vaccination caused 5-46 cases per 100 thousand children and up to 200 cases in African countries with a mortality rate of up to $40 \%$ [27]. In the world in 2000, this infection affected 8.1 million children aged $0-5$ years, while meningitis was diagnosed in $60 \%$ of cases, of which 363 thousand deaths were registered. In Russia in 2005-2007, depending on the region, $5-57 \%$ of cases of purulent meningitis caused by Hib were detected, with a mortality rate of $5-15 \%$. Up to $35 \%$ of children who have recovered suffer from persistent defects of the central nervous system, up to 5-10\% suffer from pleuropneumonia, and up to $80 \%$, from epiglottitis [28].

The first capsular polysaccharide-based Hib vaccine was licensed in the US in 1985, but was ineffective in children under 18 months of age.

Capsular Hib polysaccharides conjugated with tetanus toxoid, a nontoxic variant of diphtheria toxin, outer membrane protein of $N$. meningitidis serogroup $\mathrm{B}$, are the basis of the combined preparations Pentaxim (Sanofi Pasteur, France) and Infanrix-Hexa (Glaxo Smith Klein, Belgium) [29]. Vaccination with these drugs reduces the incidence of severe pneumonia by $20-25 \%$. However, $18 \%$ of vaccinated individuals had various complications, and $33 \%$ had low levels of protective antibodies.

Since 2013, conjugate vaccines have been used in 184 countries around the world. Despite this, up to 199 thousand deaths were recorded in the world annually, which put Hib in third place in mortality after pneumococcal and rotavirus infections [29, 30].
Currently, three vaccines based on the Hib capsular polysaccharide conjugated with tetanus toxoid are registered in the WHO registry: hemophilic type B vaccine (Rostov Research Institute of Microbiology and Parasitology, Russia), Act-Hib (Sanofi Pasteur, France) and Hiberix (Glaxo Smith Klein, Belgium) [29]. The effectiveness of these vaccines is $95-100 \%$, and the protective antibody titer lasts for at least four years.

Streptococcus pneumoniae. Diseases caused in humans by this pathogen are the most common in the world: more than one million people die every year, of which more than half are children under five years of age. In the absence of vaccination in Russia, 300700 cases of the disease are recorded per 100 thousand of the population, which is consistent with the results of foreign studies [31-33]. Pneumococcal meningitis is a particularly severe condition [28].

Currently, for the prevention of pneumococcal infection, both polysaccharide vaccines Pnevmo 23 (Sanofi Pasteur, France) and Pneumovax 23 (Merck, Sharp and Dome, United States) are used, which are a mixture of purified capsular polysaccharides of 23 most common pneumococcal serotypes, as well as vaccines based on capsular polysaccharides conjugated to a carrier protein: Prevenar 13 (Pfizer, United States) and Sinflorix-10 (Glaxo Smith-Klein, Belgium).

The use of these vaccines is largely limited due to the serotype variability and genomic plasticity that are characteristic features of this bacterium, and the increasing frequency of drug resistance of strains underlines the importance of developing a new generation of pneumococcal vaccines covering many serotypes [7, 18].

Despite the emergence of new antibiotics and vaccines, pneumococci continue to cause diseases worldwide in young children, the elderly and immunocompromised people. The high morbidity and mortality from this infection in recent decades has led to the need to develop new vaccines. Thus, it is rational to replace the entire huge arsenal of antibacterial vaccines with one monocomponent vaccine.

\section{STRUCTURE AND FUNCTIONS OF SERINE IgA1 PROTEASES}

Currently, significant progress has been achieved in the study of the structure and functions of proteins in $N$. meningitidis. The review by Tommassen et al. [34] describes the translocation systems, secretion mechanisms, and functions of a number of $N$. meningitidis proteins, including IgA1 protease, a classical autotransporter of gram-negative bacteria.

Autotransporters contain three main regions: a signal peptide, a transported domain, and a translocator domain (TD) [6, 35, 36] (Fig. 1). The transported domain of IgA1 protease is located between the signal peptide and the translocator domain and consists of 


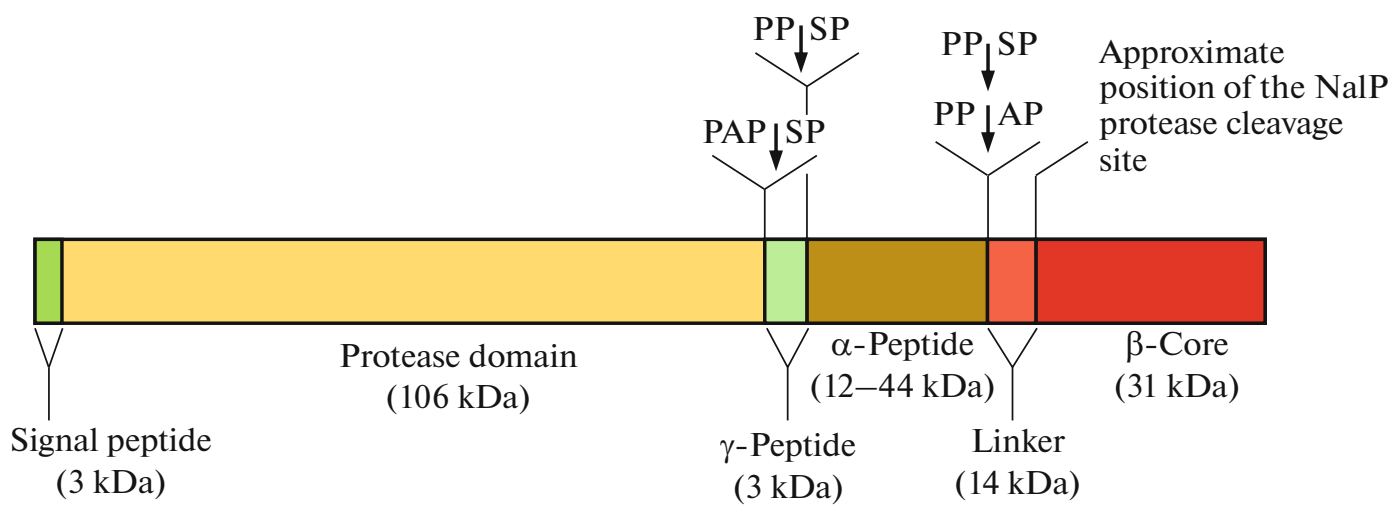

TD: linker $+\beta$-core
$(45 \mathrm{kDa})$

Fig. 1. Domain structure of IgA1 protease of H. influenzae [6]. The figure shows a schematic structure of a full-length IgA1 protease with the positions of the autocatalytic processing sites and their sequences, as well as the position of the cleavage site of NalP protease.

two subdomains: the $N$-terminal protease domain and the $\alpha$-peptide, linked by a small $\gamma$-peptide. The translocator domain is located at the $C$-terminal region of the IgA1 protease and contains a linker peptide and $\beta$-barrel. The $N$-terminal signal peptide is involved in protein transport through the cytoplasmic membrane. TD forms a channel in the outer membrane through which the transported domain is transferred into the extracellular space. On the outer membrane of bacteria, IgA1 protease undergoes autocatalytic cleavage at sites (PAPSP, PPSP, or PPAP) located between the protease domain and the $\gamma$-peptide, between the $\gamma$-peptide and the $\alpha$-peptide, and between the $\alpha$-peptide and the linker peptide. The presence of the latter processing site depends on the strain [6]. In some cases, the entire transported domain, including the linker peptide, can be released after cleavage by the autotransporter protease NalP (Fig. 1) [6, 37].

IgA1 protease cleaves human immunoglobulin A1 at the TPPTPSPS site, which is homologous to the autocatalytic processing sites and is located in the hinge region between the Fab and Fc domains [38]. IgA1 protease does not cleave IgA2 immunoglobulin, which lacks such a cleavage site (Fig. 2) [39, 40]. Cleavage of IgA1 can inhibit IgA-mediated agglutination and subsequent mechanical clearance of bacteria in the nasopharynx. It was also shown that IgA1 protease cleaves the membrane protein LAMP1 associated with lysosomes [41], which, as previously reported, promotes bacterial survival in epithelial cells [42] and transcytosis through polarized epithelium [43]. In addition, IgA1 protease cleaves the vesicular membrane protein synaptobrevin II in chromiumaffinity cells [44] and human chorionic gonadotropic hormone [45], but the physiological consequences of this cleavage are not clear. All of these alternative substrates contain a target homologous to autocatalytic cleavage sites.

The identification of bacterial $\operatorname{IgA} 1$ proteases, their protease activity, specificity and structure are described in detail in the review by Nicole et al. [36]. IgA1 proteases from $H$. influenzae, $N$. meningitidis, and $N$. gonorrhoeae have significant homology, have structures characteristic of autotransporters, and undergo autoproteolytic cleavage, which leads to the release of the transported domain from the $\beta$-cylindrical domain inserted into the membrane [35, 46-48]. IgA1 proteases of most strains of $H$. influenzae, $N$. meningitidis, and $N$. gonorrhoeae are capable of cleaving serum IgA1 and, to a lesser extent, the dimeric secretory form of IgA1. Kilian et al. [49] in their work investigated the efficiency of cleavage of immunoglobulins by extracellular strains of Haemophilus and $S$. pneumoniae and showed that $H$. influenzae and $S$. pneumoniae produce an enzyme that selectively cleaves human IgA1 myeloma proteins, but is not active against a number of other proteins, including human $\operatorname{IgA} 2, \operatorname{IgG}$, and $\operatorname{IgM}$, porcine and bovine secretory protein. None of the nonpathogenic Haemophilus strains produced IgA1 protease. Consequently, the production of IgA1 protease is an important factor in the pathogenesis of this disease.

As a reflection of the clonal population structure of encapsulated $H$. influenzae isolates, typed strains are characterized by IgA1 proteases with similar cleavage capacity. In contrast, untyped IgA1 proteases of H. influenzae (NTHi) are highly variable in respect of 


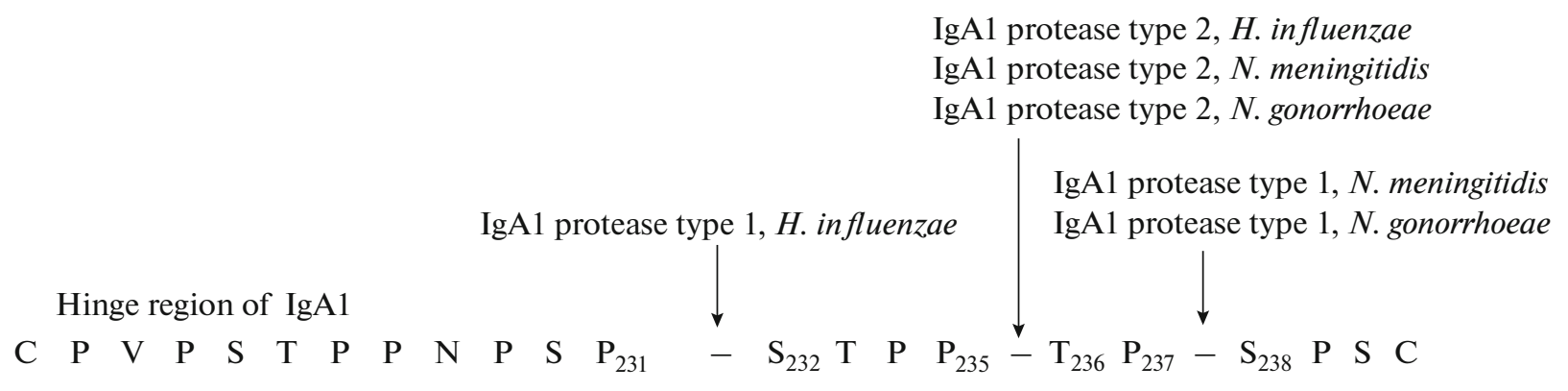

IgA1 protease type $2, H$. influenzae

IgAl protease type $2, N$. meningitidis

IgA1 protease type 2, $N$. gonorrhoeae

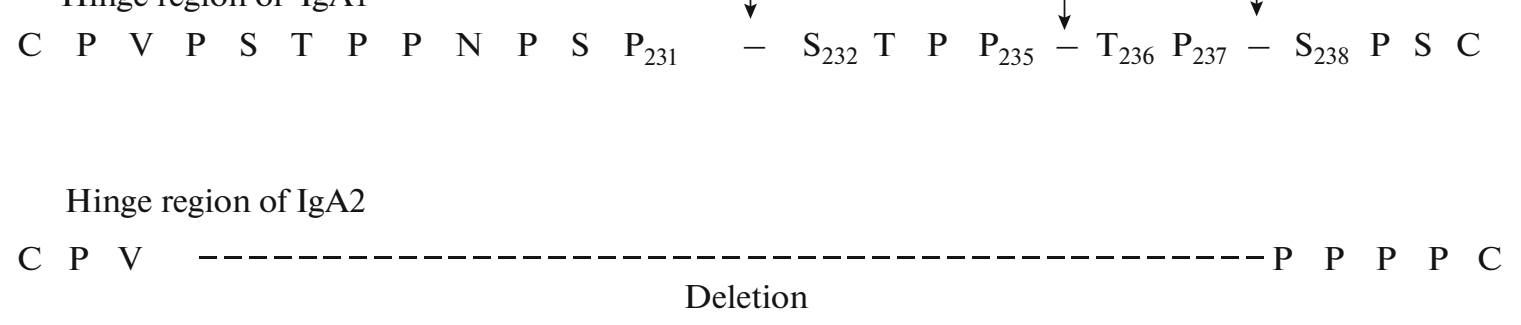

Fig. 2. Sequences of human $\operatorname{IgA} 1$ and $\operatorname{IgA} 2$ hinge peptides and location of sites of cleavage by various members of the IgA protease family [38, 39].

antigenicity, presumably due to horizontal gene transfer and recombination between several colonizing strains to evade immune defense [50, 51]. This variability leads to strain-to-strain changes in proteolytic activity for NTHi isolates from patients with a higher level of activity compared to colonizing NTHi isolates [52].

Nicole et al. [36] showed that IgA1 proteases, autotransporters Hap, Hia, and Hsf of $H$. influenzae are virulence factors that promote bacterial colonization and survival in the human body. Adhesion to the respiratory epithelium, formation of microcolonies leading to biofilm production, and protease activity promoting bacterial proliferation and immune evasion are important pathogenic mechanisms mediated by these proteins. Mechanisms by which these virulence factors can act together to accelerate infection with $H$. influenzae bacteria are described.

Hia-mediated adhesion to epithelial cells and Hapmediated adhesion to both epithelial cells and the extracellular matrix (ECM) may be responsible for initial contact with the host, while IgA1 protease cleaves IgA1, protecting bacteria from the innate immune response. As the infection progresses, HapHap protein interactions lead to the formation of microcolonies and may eventually lead to biofilm formation, which is another way of evading immunity. Due to the autoproteolytic activity of Hap, some bacteria can be released from the biofilm for colonization at another site. Finally, a Hap-mediated bacterial invasion can lead to the formation of an intracellular bacterial reservoir, which may be responsible for the recurrent infections seen in chronic obstructive pulmonary disease and otitis media. Further study of these proteins may contribute to a more detailed assessment of the development of diseases caused by the bacterium $H$. influenzae and accelerate the development of new antimicrobial drugs [36].

The three-dimensional structures of the above $H$. influenzae proteins have been investigated $[53,54]$. In the crystal structure of the transported domain, the $N$-terminal trypsin- and chymotrypsin-like protease domain and $\beta$-helical spine were identified as the main structural components. Figure 3 shows the three-dimensional structure of the $\operatorname{IgA} 1$ protease compared to the transport domain structure of the Hap protein.

The $\beta$-helical spine contains a core of hydrophobic residues and residues of serine, threonine and asparagine located on the surface of the chain and stacked into a folded structure. It serves to remove the $N$-terminal domain from the bacterial membrane. The $N$ terminal domain is characterized by a globular structure with unique loops in the folding site of the chymotrypsin domain, which are important for the selection of substrate [54], and contains a catalytic triad responsible for protease activity [53]. The active site of the protease domain creates a perfect environment for proline residues, which are usually found at specific sites for cleavage of proteins by the IgA1 protease. It should be noted that small domain 2 forms a unique loop protruding from the core of the $\beta$-helix, giving the protein a Y-shaped structure. Computational studies of the crystal structures of the IgA1 protease and human IgAl showed that the Fc domain of IgA1 binds in the groove formed by domain 2 and the protease domain, which indicates the participation of this small fragment in substrate recognition [36, 54]. A unique loop is located above the active site of the enzyme and acts as a lid closed in the absence of immunoglobulin. After binding of the Fc domain of IgA1 in the groove formed between the $N$-terminal domain of the protease and domain 2 attached to the 

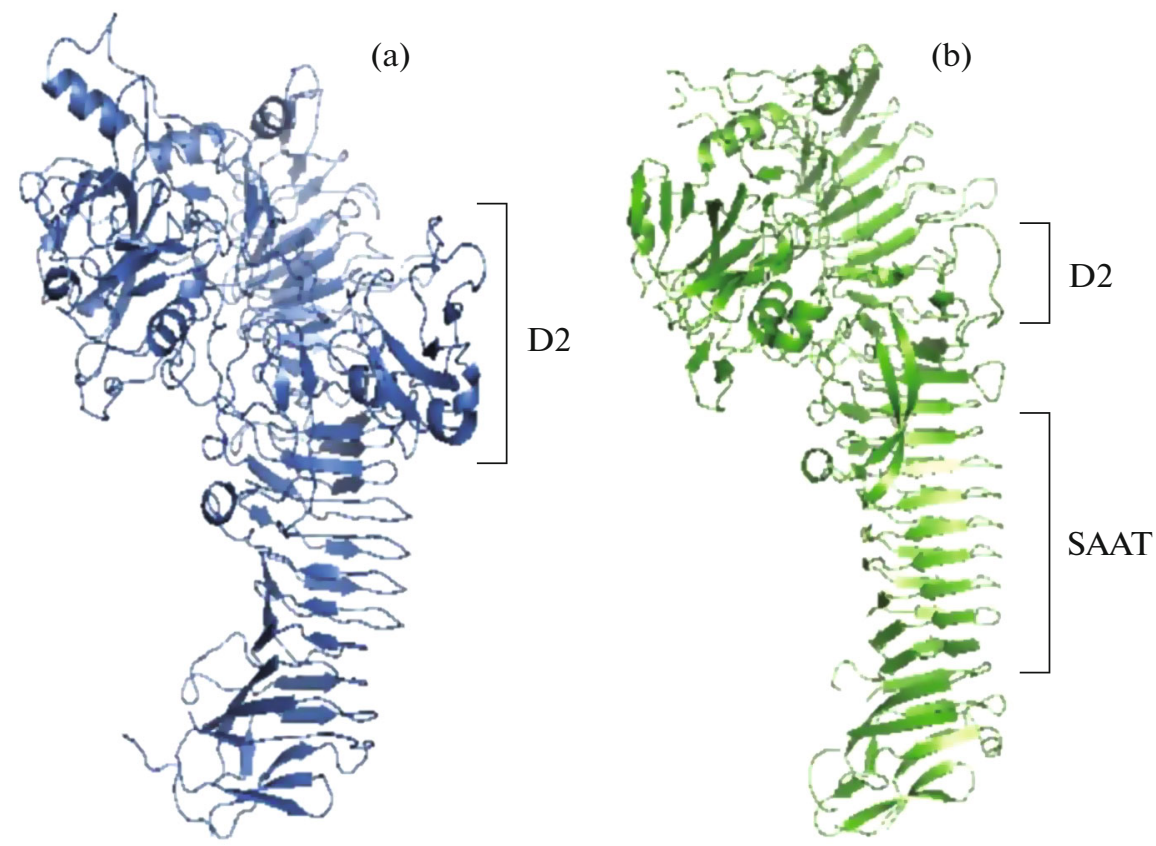

Fig. 3. Spatial structures of the transported domains of IgA1 protease and Hap [36]: (a) crystal structure of the transported domain of IgA1 protease with the $N$-terminal globular protease domain (D2); (b) crystal structure of the Hap transported domain with the $N$-terminal globular protease domain and $C$-terminal $\beta$-helical SAAT self-associating domain.

$\beta$-helical chain, the lid is stabilized in the open conformation. This interaction allows the hinge peptide to reach the active site, leading to recognition and cleavage of the substrate. This ensures the proteolytic specificity of the enzyme.

\section{IgA1 PROTEASE AND ITS FRAGMENTS AS A BASIS FOR THE CREATION OF THERAPEUTIC AND PREVENTIVE AGENTS}

Wang et al. [55] designed and obtained a highly active recombinant IgA1 protease from $H$. influenzae 49247 capable of cleaving a glycosylated IgA1-containing immune complex in vitro with the aim of possibly using the enzyme as a therapeutic agent for the treatment of IgA nephropathy. The severity of impairment of renal function, such as proteinuria and hematuria, can also be reduced by injections of IgA1 protease [56].

In 2007, Vitovski et al. [57] obtained a number of meningococcal IgA1 protease precursors. Autocatalytic activation of this enzyme has been studied in detail, but the immunogenic and protective properties of the proteins obtained have not been studied, and the possibility of their use as a vaccine has also not been considered.

Wani et al. [58] showed for the first time the activity of the recombinant forms of the IgA1 protease of pneumococcus and identified specific inhibitors that prevent the colonization of the mucous membrane by pneumococcus, and the inactive mutant was considered as a component of a candidate vaccine.

Romanello et al. [59] showed that the IgA1 protease of pneumococci is associated with the bacterial cell surface by an $N$-terminal membrane anchor. The cloning, expression, enzymatic activity and immunogenicity of three IgA1 protease fragments, of which one contains only amino acids of the $N$-terminal region, were described. All obtained mutants were completely devoid of enzymatic activity. The authors tested the antigenic properties of recombinant polypeptides with sera from patients diagnosed with pneumonia of various etiologies. Antibodies to the fragment of IgA1 protease (1032-1964 amino acid residues) were found in the sera of five patients out of nine, and antibodies to the fragment of IgA1 protease (708-1964 amino acid residues) were found in seven patients. Full-length IgA1 protease detected antibodies in all sera, indicating that IgA1 protease is the main antigen of $S$. pneumoniae in human pathogenesis. These fragments, as well as IgA1 protease, are surface proteins present in almost all pneumococcal serotypes. The authors concluded that these recombinant proteins could be candidates for an anti-pneumococcal vaccine.

The synthesis of $N$-terminal fragments of IgA1 protease from $N$. meningitidis serogroup A, containing 40-104 amino acid residues, was described [60], which were used as peptide-carriers of carbohydrate components of the cell walls of various microorganisms: Neisseria, Streptococcus, Klebsiella, Salmonella, 
Shigella, and Haemophilus. But the conjugation of these fragments with the polysaccharide of meningococcus serogroup $\mathrm{C}$ of did not allow obtaining polyvalent compositions. They provided protection only against meningococcus serogroup $\mathrm{C}$.

To treat autoimmune and other diseases associated with the accumulation of IgA1 in human tissues and organs, soluble forms of IgA1 protease were obtained by the method of recombinant DNA [61, 62]. The authors used them as therapeutic agents, but did not consider them as a vaccine.

Gupta et al. [63] described the results of computer analysis of potential T-cell epitopes of three proteins of meningococcus serogroup B: T-cell stimulating protein A (TspA), autotransport protein A (AutA), and IgA1 protease. As a result of the study, six nine-membered T-cell epitopes were identified. The authors suggested that these peptides can be used as promising agents for protection against meningococci of the serogroup B, but experimental data confirming this hypothesis are not presented in the work, and the possibility of obtaining a multivalent vaccine based on them was also not discussed.

Later, many authors suggested that $\operatorname{IgA} 1$ protease is the most important factor in bacterial virulence and can be used as a means of protection against these pathogens [17, 63].

Experimental confirmation of the protective activity of $\operatorname{IgA} 1$ protease is shown in a small number of works. In a series of works [64-74] in animal experiments, it was shown that native IgA1 protease isolated from a live virulent culture of $N$. meningitidis serogroup A, as well as recombinant IgA1 proteases of $N$. meningitidis serogroup B in active or mutant forms, and some truncated analogs of these proteins have high immunogenic and protective activity.

On the example of individual low-molecularweight fragments of IgA1 protease, an important role of B and $\mathrm{T}$ epitopes located in the $N$-terminal region of IgA1 protease of $N$. meningitidis serogroup B (strain $\mathrm{H} 44 / 76$ ) for the preservation of immunogenic and protective properties was demonstrated [64, 65]. These proteins protected mice from infection with a live virulent culture of meningococci of the main epidemic serogroups (A, B, and C) and had the characteristic ability of proteins to form immunological memory $[68,69,73]$.

In experiments with acute infection of animals, the role of cellular and humoral factors in the formation of immunity to meningococcus of the serogroup B was shown. The immunized animals were protected by both immune lymphocytes and specific antibodies capable of binding in vitro to IgA1 protease of $N$. meningitidis [69].

It was also shown that specific antibodies formed upon immunization of animals with IgA1 protease analogs or upon infection with meningococcus are capable of binding not only to the secreted enzyme, but also to the surface of microbial cells [66].

Analysis of the population composition of lymphocytes $\left(\mathrm{CD}^{+}, \mathrm{CD}^{+}\right.$, and $\left.\mathrm{CD} 19^{+}\right)$in the blood and spleen of immunized animals at the time of meningococcal infection showed that the defense mechanism is caused by different populations of lymphocytes, depending on the structure of immunogens [69].

Similar results were obtained when studying streptococcal IgA1 metalloproteases to protect animals from diseases caused by pneumococci and $S$. suis serotype 2 . The authors consider this protein and its fragments as a protective surface antigen of IgA1 protease $[5,75]$.

A group of authors [75-78] investigated the antigenic composition and similarity of IgA 1 proteases of various representatives of serine-type microbes and metalloproteases, the pathogenicity of which is caused by IgA1 protease. High similarity of epitopes of IgA1 proteases of $N$. meningitidis and $N$. gonorrhoeae was found, which makes them attractive components of a potential vaccine of a wide profile. The similarity of these epitopes with IgA1 metalloproteases of $S$. pneumoniae turned out to be insignificant [77].

Later Kotelnikova et al. [68] found that immunization of animals with IgA1 protease of $N$. meningitidis and its analogs is capable of providing the formation of immunological memory and protection from fatal contagion not only with meningococcal, but also with pneumococcal infections. In contrast, the sera of rabbits immunized with the killed $S$. pneumoniae culture contained high titers of protective antibodies to IgA1 protease of $N$. meningitidis and its fragments.

These results are of particular interest, since IgA1 protease of $S$. pneumoniae belongs to the class of metalloproteases and significantly differs in amino acid sequence from the serine IgA1 proteases secreted by $N$. meningitidis, $N$. gonorrhoeae, and $H$. influenzae. The protective activity of meningococcal IgA1 protease and its analogs upon infection of animals with $S$. pneumoniae may depend on the presence of conformational epitopes in these proteins that are structurally similar to the epitopes of the surface proteins of pneumococci. In addition, secreted proteases can have several targets and, thus, interfere with the metabolism and immune response of the host in different ways $[34,79,80]$.

\section{CONCLUSIONS}

Analysis of literature data showed that the development of vaccines against bacterial meningitis based on the surface antigens of microorganisms that cause these diseases has led to the creation of a number of effective drugs with a strictly targeted action against a specific pathogen. The search for new vaccine antigens stimulated studies of not only surface, but also secreted proteins. An interesting direction has become 
the study of IgA1 protease as one of the main virulence factors contributing to the colonization and survival of microorganisms in the human body. Neutralization of IgA1 protease at this stage of invasion can become an obstacle to the development of infections, the pathogenicity of which is caused by this enzyme. IgA1 protease promotes the interaction of the pathogen with the host (adhesion to the cells of the host organism, evasion from the formation of acquired immunity, prevention of complement activation, neutralization of antimicrobial peptides, degradation of immunoglobulins, etc.).

The presented data on the properties of IgA1 proteases of a number of pathogenic microorganisms showed that the high immunogenic and protective activity of recombinant variants of the enzyme and some of its fragments against gram-negative (N. meningitidis, $N$. gonorrhoeae, $H$. influenzae) and some gram-positive ( $S$. pneumoniae, $S$. suis) bacteria, in combination with a high homology of conserved regions of the primary structure of full-length IgA1 proteases, suggest the possibility of the formation of cross immunity to various pathogens, the pathogenicity of which is caused by IgAl protease. The above studies indicate the possibility and feasibility of creating a monocomponent vaccine with a broad spectrum of action against a number of bacterial infections.

\section{FUNDING}

This work was financially supported by the Russian Science Foundation (grant no. 14-50-00131).

\section{COMPLIANCE WITH ETHICAL STANDARDS}

In carrying out this work, all ethical standards were observed. This article does not contain any studies involving humans and animals as objects.

\section{Conflict of Interests}

The authors declare that they have no conflicts of interest.

\section{OPEN ACCESS}

This article is licensed under a Creative Commons Attribution 4.0 International License, which permits use, sharing, adaptation, distribution and reproduction in any medium or format, as long as you give appropriate credit to the original author(s) and the source, provide a link to the Creative Commons licence, and indicate if changes were made. The images or other third party material in this article are included in the article's Creative Commons licence, unless indicated otherwise in a credit line to the material. If material is not included in the article's Creative Commons licence and your intended use is not permitted by statutory regulation or exceeds the permitted use, you will need to obtain permission directly from the copyright holder. To view a copy of this licence, visit http://creativecommons.org/licenses/by/4.0/.

\section{REFERENCES}

1. Henderson, I.R. and Nataro, J.P., Infect. Immun., 2001, vol. 69, pp. 1231-1243.

https://doi.org/10.1128/IAI.69.3.1231-1243.2001

2. Kazeeva, T.N. and Shevelev, A.B., Biochemistry (Moscow), 2007, vol. 72, pp. 485-494. https://doi.org/10.1134/s0006297907050045

3. Mistry, D. and Stockley, R.A., Int. J. Biochem. Cell Biol., 2006, vol. 38, pp. 1244-1248.

https://doi.org/10.1016/j.biocel.2005.10.005

4. Plaut, A.G. and Bachovchin, W.W., Methods Enzymol., 1994, vol. 244, pp. 137-151.

https://doi.org/10.1016/0076-6879(94)44012-3

5. Lei, F., Zhao, J., Lin, L., Zhang, Q., Xu, Z., Han, L., Xie, C., Zhou, R., Jin, M., and Zhang, A., Microbes Infect., 2016, vol. 18, pp. 285-289.

https://doi.org/10.1016/j.micinf.2015.12.005

6. Roussel-Jazédé, V., Arenas, J., Langereis, J.D., Tommassen, J., and van Ulsen, P., Microbiology, 2014, vol. 160 , pp. $2421-2431$. https://doi.org/10.1099/mic.0.082511-0

7. Kilian, M., Thomsen, B., Petersen, T.E., and Bleeg, H., Mol. Immunol., 1983, vol. 20, pp. 1051-1058.

https://doi.org/10.1016/0161-5890(83)90046-9

8. Meningococcal Vaccines: WHO Position Paper, November 2011, Wkly Epidemiol. Rec., 2011, vol. 86, pp. 521-539.

9. Erickson, L.J., De Wals, P., McMahon, J., and Heim, S., Clin. Infect. Dis., 2001, vol. 33, pp. 737-739.

https://doi.org/10.1086/322587

10. Edwards, M.S. and Baker, C.J., J. Pediatr., 1981, vol. 99 , pp. $540-545$.

https://doi.org/10.1016/s0022-3476(81)80250-8

11. Agrawal, S. and Nadel, S., Pediatr. Drugs, 2011, vol. 13, pp. 385-400.

https://doi.org/10.2165/11593340-000000000-00000

12. Stephens, D.S. and Apicella, M.A., in Mandell Douglas and Bennett's Principles and Practice of Infectious Diseases, Bennett, J.E., Dolin, R., Blaser, M.J, Eds., Philadelphia: Elsevier Saunders, 2015, pp. 2425-2445.

13. Marchiafava, E. and Celli, A., Gazz. Degli Ospedali, 1884, vol. 5, p. 59.

14. Weichselbaum, A., Fortschr. Med., 1887, vol. 5, pp. 573-583.

15. Pace, D. and Pollard, A.J., Vaccine, 2012, vol. 30, pp. B3-B9. https://doi.org/10.1016/j.vaccine.2011.12.062

16. Takada, S., Fujiwara, S., Inoue, T., Kataoka, Yu., Hadano, Y., Matsumoto, K., Morino, K., and Shimizu, T., Intern. Med., 2016, vol. 55, pp. 567-572.

https://doi.org/10.2169/internalmedicine.55.3272

17. Rouphael, N.G. and Stephens, D.S., Methods Mol. Biol., 2012, vol. 799, pp. 1-20.

https://doi.org/10.1007/978-1-61779-346-2_1

18. Crum-Cianflone, N. and Sullivan, E., Infect. Dis. Ther., 2016, vol. 5, pp. 89-112.

https://doi.org/10.1007/s40121-016-0107-0 
19. Girard, M.P., Preziosi, M.P., Aguado, M.T., and Kieny, M.P., Vaccine, 2006, vol. 24, pp. 4692-4700. https://doi.org/10.1016/j.vaccine.2006.03.034

20. Thigpen, M.C., Whitney, C.G., Messonnier, N.E., Zell, E.R., Lynfield, R., Hadler, J.L., Harrison, L.H., Farley, M.M., Reingold, A., Bennett, N.M., Craig, A.S., Schaffner, W., Thomas, A., Lewis, M.M., Scallan, E., Schuchat, A., and Emerging Infections Programs Network, N. Engl. J. Med., 2011, vol. 364, pp. 2016-2025. https://doi.org/10.1056/nejmoa1005384

21. Caron F., du Châtelet, I.P., Leroy, J.P., Ruckly, C., Blanchard, M., Bohic, N., Massy, N., Morer, I., Floret, D., Delbos, V., Hong, E., Révillion, M., Berthelot, G., Lemée, L., Deghmane, A.E., Bénichou, J., LévyBruhl, D., and Taha, M.K., Lancet Infect. Dis., 2011, vol. 11 , pp. 455-463. https://doi.org/10.1016/s1473-3099(11)70027-5

22. Koroleva, I.S., Beloshitskii, G.V., Zakroeva, I.M., and Koroleva, M.A., Infekts. Immun., 2012, vol. 2, pp. 546547.

23. Gossger, N., Snape, M.D., Yu, L.M., Finn, A., Bona, G., Esposito, S., Principi, N., Diez-Domingo, J., Sokal, E., Becker, B., Kieninger, D., Prymula, R., Dull, P., Ypma, E., Toneatto, D., Kimura, A., Pollard, A.J., and European MenB Vaccine Study Group, JAMA, 2012, vol. 307, pp. 573-582.

https://doi.org/10.1001/jama.2012.85

24. Granoff, D.M., Clin. Infect. Dis., 2010, vol. 50, pp. S54-S65.

https://doi.org/10.1086/648966

25. Holst, J., Oster, P., Arnold, R., Tatley, M.V., Næss, L.M., Aaberge, I.S., Galloway, Y., Mcnicholas, A., O'Hallahan, J., Rosenqvist, E., and Black, S., Hum. Vaccin. Immunother., 2013, vol. 9, pp. 1241-1253. https://doi.org/10.4161/hv.24129

26. Folaranmi, T., Rubin, L., Martin, S.W., Patel, M., Macneil, J.R., and Centers for Disease Control (CDC), MMWR Morb. Mortal. Wkly Rep., 2015, vol. 64, pp. 608-612.

27. Haemophilus influenzae Type B Immunization, Bulletins du Centre International de L'enfance, 1992, pp. 33-34.

28. Platonov, A.E., Kharit, S.M., and Platonova, O.V., Epidemiol. Vaktsinoprofilakt., 2009, no. 5, pp. 32-46.

29. Ozeretskovskii, N.A. and Nemirovskaya, T.I., Epidemiol. Vaktsinoprofilakt., 2016, vol. 15, pp. 61-66. https://doi.org/10.31631/2073-3046-2016-15-1-61-66

30. Haemophilus influenzae Type B (Hib). Green Book. Immunizaition against Infections Disease, 2013, part 2, ch. 16, pp. 127-143.

31. Kozlov, R.S., Pnevmokokki: proshloe, nastoyashchee $i$ budushchee (Pneumococci: Past, Present, and Future), Smolensk: Smolenskaya Gosudarstvennaya Meditsinskaya Akademiya, 2005.

32. Tatochenko, V.A., Vopr. Sovr. Pediatr., 2007, vol. 6, pp. 85-91.

33. Clark, J.E., Hammal, D., Hampton, F., Spencer, D., and Parker, L., Epidemiol. Infect., 2007, vol. 135, pp. 262-269.

https://doi.org/10.1017/s0950268806006741

34. Tommassen, J. and Arenas, J., Front. Cell. Infect. Microbiol., 2017, vol. 7, p. 256.

https://doi.org/10.3389/fcimb.2017.00256
35. Pohlner, J., Halter, R., Beyreuther, K., and Meyer, T.F., Nature, 1987, vol. 325, pp. 458-462. https://doi.org/10.1038/325458a0

36. Spahich, N.A. and Geme, J.W.St., 3rd, Front. Cell. Infect. Microbiol., 2011, vol. 1, pp. 1-9.

https://dx.doi.org/10.3389\%2Ffcimb.2011.00005

37. van Ulsen, P., van Alphen, L., Hove, J., Fransen, F., van der Ley, P., and Tommassen, J., Mol. Microbiol., 2003, vol. 50, pp. 1017-1030. https://doi.org/10.1046/j.1365-2958.2003.03773.x

38. Plaut, A.G., Gilbert, J.V., Artenstein, M.S., and Capra, J.D., Science, 1975, vol. 190, pp. 1103-1105. https://doi.org/10.1126/science.810892

39. Boehm, M.K., Woof, J.M., Kerr, M.A., and Perkins, S.J., J. Mol. Biol., 1999, vol. 286, pp. 1421-1447. https://doi.org/10.1006/jmbi.1998.2556

40. Torano, A. and Putnam, F.W., Proc. Natl. Acad. Sci. U. S. A., 1978, vol. 75, pp. 966-969. https://doi.org/10.1073/pnas.75.2.966

41. Hauck, C.R. and Meyer, T.F., FEBS Lett., 1997, vol. 405, pp. 86-90. https://doi.org/10.1016/s0014-5793(97)00163-4

42. Lin, L., Ayala, P., Larson, J., Mulks, M., Fukuda, M., Carlsson, S.R., Enns, C., and So, M., Mol. Microbiol., 1997, vol. 24, pp. 1083-1094. https://doi.org/10.1046/j.1365-2958.1997.4191776.x

43. Hopper, S., Vasquez, B., Merz, A., Clary, S., Wilbur, J.S., and So, M., Infect. Immun., 2000, vol. 68, pp. 906-911. https://doi.org/10.1128/iai.68.2.906-911.2000

44. Binscheck, T., Bartels, F., Bergel, H., Bigalke, H., Yamasaki, S., Hayashi, T., Niemann, H., and Pohlner, J., J. Biol. Chem., 1995, vol. 270, pp. 1770-1774. https://doi.org/10.1074/jbc.270.4.1770

45. Senior, B.W., Stewart, W.W., Galloway, C., and Kerr, M.A., J. Infect. Dis., 2001, vol. 184, pp. 922-925. https://doi.org/10.1086/323397

46. Grundy, F.J., Plaut, A.G., and Wright, A., Adv. Exp. Med. Biol., 1987, vol. 216B, pp. 1251-1260.

47. Poulsen, K., Brandt, J., Hjorth, J.P., Thogersen, H.C., and Kilian, M., Infect. Immun., 1989, vol. 57, pp. 3097-3105.

https://doi.org/10.1128/iai.57.10.3097-3105.1989

48. Plaut, A.G., Qiu, J., and Geme, J.W. St., 3rd, Vaccine, 2000, vol. 19, suppl. 1, pp. S148-S152.

https://doi.org/10.1016/s0264-410x(00)00296-6

49. Kilian, M., Mestecky, J., and Schrohenloher, R.E., Infect. Immun., 1979, vol. 26, pp. 143-149.

https://doi.org/10.1128/iai.26.1.143-149.1979

50. Musser, J.M., Barenkamp, S.J., Granoff, D.M., and Selander, R.K., Infect. Immun., 1986, vol. 52, pp. 183191.

https://doi.org/10.1128/iai.52.1.183-191.1986

51. Lomholt, H., van Alphen, L., and Kilian, M., Infect. Immun., 1993, vol. 61, pp. 4575-4581. https://doi.org/10.1128/iai.61.11.4575-4581.1993

52. Vitovski, S., Dunkin, K.T., Howard, A.J., and Sayers, J.R., JAMA, 2002, vol. 287, pp. 1699-1705. https://doi.org/10.1001/jama.287.13.1699

53. Perona, J.J. and Craik, C.S., Protein Sci., 1995, vol. 4, pp. 337-360.

https://doi.org/10.1002/pro.5560040301 
54. Johnson, T.A., Qiu, J., Plaut, A.G., and Holyoak, T., J. Mol. Biol., 2009, vol. 389, pp. 559-574.

https://doi.org/10.1016/j.jmb.2009.04.041

55. Wang, H., Zhong, X., Li, J., Zhu, M., Wang, L., Ji, X., Fan, J., and Wang, L., Mol. Biotechnol., 2018, vol. 60, pp. $134-140$. https://doi.org/10.1007/s12033-017-0054-3

56. Lechner, S.M., Abbad, L., Boedec, E., Papista, C., Le Stang, M.B., Moal, C., Maillard, J., Jamin, A., BexCoudrat, J., Wang, Y., Li, A., Martini, P.G., Monteiro, R.C., and Berthelot, L., J. Am. Soc. Nephrol., 2016, vol. 27, pp. $2622-2629$. https://doi.org/10.1681/asn.2015080856

57. Vitovski, S. and Sayers, J.R., Infect. Immun., 2007, vol. 75, pp. 2875-2885. https://doi.org/10.1128/iai.01671-06

58. Wani, J.H., Gilbert, J.V., Plaut, A.G., and Weiser, J.N., Infect. Immun., 1996, vol. 64, pp. 3967-3974. https://doi.org/10.1128/iai.64.10.3967-3974.1996

59. Romanello, V., Marcacci, M., Moschioni, M., Censini, S., Covacci, A., Baritussio, A.G., Montecucco, C., and Tonello, F., Protein Expr. Purif., 2006, vol. 45, pp. 142-149.

https://doi.org/10.1016/j.pep.2005.07.015

60. Achtman, M. and Moreau, M., US Patent no. 7235242 B2, 2007.

61. Long, S., Phan, E., and Vellard, M.C., J. Biomed. Biotechnol., 2010, vol. 2010, pp. 1-9. https://doi.org/10.1155/2010/253983

62. Plaut, A.G. and Qiu, J., US Patent no. 7407653, 2008.

63. Gupta, S.K., Smita, S., Sarangi, A.N., Srivastava, M., Akhoond, B.A., Rahman, Q., and Gupta, S.K., Vaccine, 2010, vol. 28, pp. 7092-7097. https://doi.org/10.1016/j.vaccine.2010.08.005

64. Zinchenko, A.A., Alliluev, A.P., Serova, O.P., Gordeeva, E.A., Zhigis, L.S., Zueva, V.S., Razgulyaeva, O.A., Melikhova, T.D., Nokel, E.A., Drozhzhina, E.Yu., Kotelnikova, O.V., and Rumsh, L.D., J. Meningitis, 2015, vol. 1 , pp. $1-5$. https://doi.org/10.4172/2572-2050.1000102

65. Zinchenko, A.A., Kotelnikova, O.V., Gordeeva, E.A., Prokopenko, Yu.A., Razgulyaeva, O.A., Serova, O.V., Melikhova, T.D., Nokel, E.A., Zhigis, L.S., Zueva, V.S., Alliluev, A.P., and Rumsh, L.D., Russ. J. Bioorg. Chem., 2018, vol. 44, pp. 64-72. https://doi.org/10.1134/S1068162018010193

66. Kotelnikova, O.V., Zinchenko, A.A., Vikhrov, A.A., Alliluev, A.P., Serova, O.V., Gordeeva, E.A., Zhigis, L.S., Zueva, V.S., Razgulyaeva, O.A., Melikhova, T.D., Nokel, E.A., Drozhzhina, E.Y., and Rumsh, L.D., Bull. Exp. Biol. Med., 2016, vol. 161, pp. 391-394. https://doi.org/10.1007/s10517-016-3422-2

67. Serova, O.V., Mel'nikov, E.E., Zinchenko, A.A., Kotel'nikova, O.V., Alliluev, A.P., Bichucher, A.M., Gordeeva, E.A., Zhigis, L.S., Zueva, V.S., Kozlov, L.V., Melikhova, T.D., Nokel', E.A., Yagudaeva, E.Yu., and Rumsh, L.D., Biofarm. Zh., 2011, vol. 3, pp. 42-47.

68. Kotelnikova, O.V., Alliluev, A.P., Zinchenko, A.A., Zhigisa, L., Prokopenko, Y., Nokel, E.A., Razgulyaeva, O.A., Zueva, V.S., Tokarskaya, M., Yastrebova, N., Gordeeva, E.A., Melikhova, T.D., Kaliberda, E.N., and Rumsh, L.D., Microbes Infect., 2019, vol. 21, pp. $336-340$.

https://doi.org/10.1016/j.micinf.2019.02.003

69. Kotel'nikova, O.V., Alliluev, A.P., Zinchenko, A.A., Prokopenko, Yu.A., Zhigis, L.S., Zueva, V.S., Razgulyaeva, O.A., Gordeeva, E.A., and Melikhova, T.D., Nokel' E.A., Rumsh, L.D., Bull. Exp. Biol. Med., 2018, vol. 165, pp. 763-766. https://doi.org/10.1007/s10517-018-4260-1

70. Kotel'nikova, O.V., Alliluev, A.P., Drozhzhina, E.Yu., Koroleva, I.S., Sitnikova, E.A., Zinchenko, A.A., Gordeeva, E.A., Melikhova, T.D., Nokel', E.A., Zhigis, L.S., Zueva, V.S., Razgulyaeva, O.A., Serova, O.V., Yagudaeva, E.Yu., and Rumsh, L.D., Biomed. Khim., 2014, vol. 60, pp. 479-486 https://doi.org/10.18097/pbmc20146004479

71. Rumsh, L.D., Mel'nikov, E.E., Alliluev, A.P., Kozlov, L.V., Kotel'nikova, O.V., Zhigis, L.S., Serova, O.V., Yagudaeva, E.Yu., Bichucher, A.M., Zubov, V.P., Anokhina, I.V., Zueva, V.S., and Avakov, A.E., RF Patent no. $2453599 \mathrm{C} 1,2012$.

72. Rumsh, L.D., Serova, O.V., Zinchenko, A.A., Alliluev, A.P., Kozlov, L.V., Kotel'nikova, O.V., Zhigis, L.S., Yagudaeva, E.Yu., Andinina, S.S., Anokhina, I.V., Zueva, V.S., Gordeeva, E.A., Melikhova, T.D., and Nokel', E.A., RF Patent no. 2486243 C1, 2013.

73. Zinchenko, A.A., Serova, O.V., Prokopenko, Yu.A., Gordeeva, E.A., Melikhova, T.D., Nokel', E.A., Kaliberda, E.N., Kotel'nikova, O.V., Zhigis, L.S., Razgulyaeva, O.A., Alliluev, A.P., and Rumsh, L.D., RF Patent no. 2701964 C2, 2019.

74. Zhigis, L.S., Kotel'nikova, O.V., Vikhrov, A.A., Zinchenko, A.A., Serova, O.V., Zueva, V.S., Razgulyaeva, O.A., Gordeeva, E.A., Melikhova, T.D., Nokel, E.A., Alliluev, A.P., Drozhzhina, E.Yu., and Rumsh, L.D., Biotechnol. Lett., 2015, vol. 37, pp. 2289-2293. https://doi.org/10.1007/s10529-015-1916-z

75. Janoff, E.N., Rubins, J.B., Fasching, C., Charboneau, D., Rahkola, J.T., Plaut, A.G., and Weiser, J.N., Mucosal Immunol., 2014, vol. 7, pp. 249-256. https://doi.org/10.1038/mi.2013.41

76. Lomholt, H. and Kilian, M., Infect. Immun., 1994, vol. 62 , pp. $3178-3183$. https://doi.org/10.1128/iai.62.8.3178-3183.1994

77. Lomholt, H., Poulsen, K., and Kilian, M., Mol. Microbiol., 1995, vol. 15, pp. 495-506.

https://doi.org/10.1111/j.1365-2958.1995.tb02263.x

78. Lomholt, J.A. and Kilian, M., J. Clin. Microbiol., 2000, vol. 38, pp. $2760-2762$. https://doi.org/10.1128/jcm.38.7.2760-2762.2000

79. Kazeeva, T.N., Shevelev, A.B., Leonovich, O.A., Faizov, T.Kh., Belyakova, A.V., Lebedeva, A.A., Kuznetsova, T.V., Marakasova, E.S., Ermokhina, O.V., Epova, E.Yu., Dudorova, M.G., Sotskova, D.V., Volkova, E.A., Terekhina, A.S., Voronova, T.Yu, and Vasil'ev, I.A., Sovrem. Probl. Nauki Obraz., 2012, no. 1. https://www.science-education.ru/ru/article/view?id=5096.

80. Pérez-Ortega, J., Rodríguez, A., Ribes, E., Tommassen, J., and Arenas, J., Front. Microbiol., 2017, vol. 8, p. 434.

https://doi.org/10.3389/fmicb.2017.00434

Translated by A. Ostyak 